\title{
GEORGIAN MATHEMATICAL JOURNAL
}

\section{EDITOR-IN-CHIEF}

Ivan Kiguradze, Tbilisi

\section{EXECUTIVE EDITOR}

Tengiz Shervashidze, Tbilisi

EDITORIAL SECRETARY

Maia Kvinikadze, Tbilisi

\section{EDITORIAL BOARD}

Hans-Joachim Baues, Bonn

Nodar Berikashvili, Tbilisi

Oleg V. Besov, Moscow

Bogdan Bojarski, Warsaw

Tengiz Buchukuri, Tbilisi

Roland Duduchava, Tbilisi

Hans-Jürgen Engelbert, Jena

Revaz Gamkrelidze, Moscow

Joseph Gubeladze, San Francisco

Hvedri Inassaridze, Tbilisi

Mamuka Jibladze, Tbilisi

Tornike Kadeishvili, Tbilisi

Otto H. Kegel, Freiburg

Alexander Kharazishvili, Tbilisi
Sergo Kharibegashvili, Tbilisi

Estate Khmaladze, Wellington

Tariel Kiguradze, Melbourne

Vakhtang Kokilashvili, Tbilisi

Samuel Krushkal, Ramat Gan

Jaroslav Kurzweil, Prague

Stanislaw Kwapien, Warsaw

Hans Rudolf Lerche, Freiburg

Jean Mawhin, Louvain-la-Neuve

Paolo Emilio Ricci, Rome

Vaja Tarieladze, Tbilisi

Hans Triebel, Jena

Nicholas Vakhania, Tbilisi

Fabio Zanolin, Udine 
GEORGIAN MATHEMATICAL JOURNAL publishes research articles of best scientific standard in pure and applied mathematics. Special emphasis is put on the presentation of results obtained by Georgian mathematicians.

All information regarding notes for contributors, subscriptions, Open access, back volumes and orders is available online at www.degruyter.com/gmj.

ABSTRACTED/INDEXED IN Celdes • CNKI Scholar (China National Knowledge Infrastucture) • CNPIEC • EBSCO Discovery Service • Elsevier: SCOPUS • Google Scholar • J-Gate • Mathematical Reviews (MathSciNet) • Naviga (Softweco) • Primo Central (ExLibris) • SCImago (SJR)

- Summon (Serials Solutions/ProQuest) • TDOne (TDNet) • Thomson Reuters: Journal Citation Reports/Science Edition; Science Citation Index Expanded • WorldCat (OCLC) • Zentralblatt Math.

ISSN 1072-947X · e-ISSN 1572-9176 · CODEN GMJOE5

RESPONSIBLE EDITOR Tengiz Shervashidze, A. Razmadze Mathematical Institute of I. Javakhishvili Tbilisi State University, M. Tamarashvili Str. 6, 0177 Tbilisi, Georgia.

Email: gmj@rmi.ge

JOURNAL MANAGER Katharina Kaupen, De Gruyter, Genthiner Straße 13, 10785 Berlin, Germany.

Tel.: +49 (0)30 260 05-385, Fax: +49 (0)30 260 05-250

Email: katharina.kaupen@degruyter.com

RESPONSIBLE FOR ADVERTISEMENTS Claudia Neumann, De Gruyter, Genthiner Straße 13, 10785 Berlin, Germany.

Tel.: +49 (0)30 260 05-226, Fax: +49 (0)30 260 05-322

Email: anzeigen@degruyter.com

(C) 2014 Walter de Gruyter GmbH, Berlin/Boston

TYPESETTING Dimler \& Albroscheit, Müncheberg

PRINTING Franz X. Stückle Druck und Verlag e.K., Ettenheim

Printed in Germany

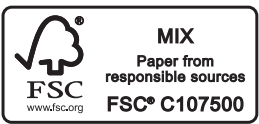




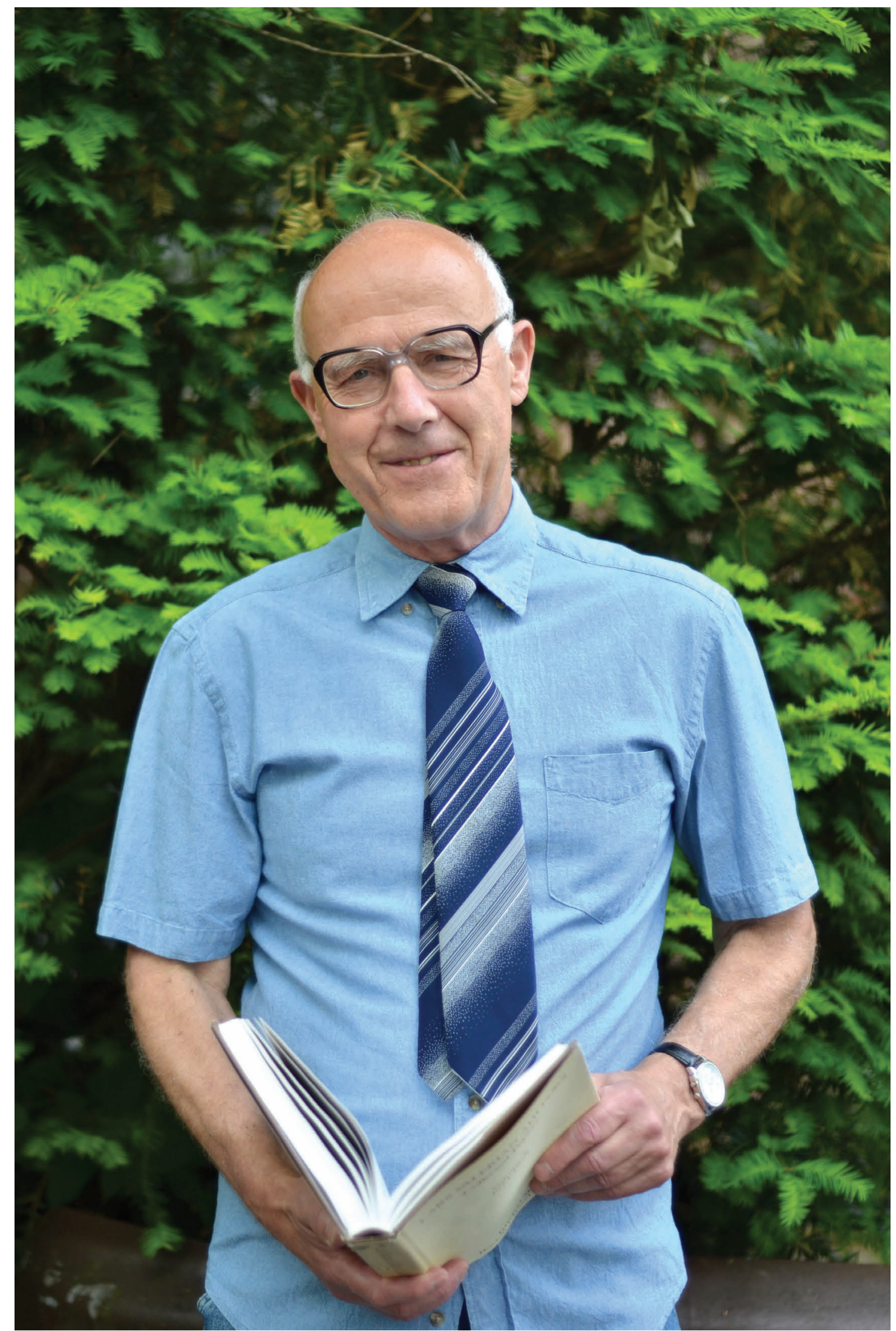

This issue is dedicated to

PROFESSOR SAMUEL L. KRUSHKAL

on the occasion of his 75th birthday. 


\section{Contents}

Bashir Ahmad, Juan J. Nieto

A class of differential equations of fractional order with multi-point boundary conditions -243

Zalman Balanov, Yakov Krasnov

Complex structures in algebra, topology and differential equations -249

Bingmao Deng, Dan Liu, Degui Yang

Normality and the differential polynomial of meromorphic functions -261

Bodo Dittmar

Characterization of the Robin function by extremal problems -267

Anatoly Golberg, Ruslan Salimov

Extension of the Schwarz Lemma to homeomorphisms with controlled $p$-module -273

Michael Kapovich

Energy of harmonic functions and Gromov's proof of Stallings' theorem -281

Alexander Kharazishvili

A characterization of uncountable sets in terms of their self-mappings and large invariant subsets — 297
Ivan Kiguradze, Zaza Sokhadze

Positive solutions of periodic type boundary value problems for first order singular functional differential equations -303

Samuel L. Krushkal

Milin's coefficients, complex geometry of Teichmüller spaces and variational calculus for univalent

functions -313

Reiner Kühnau

Potential flow and conformal distortion theory _ 333

Elijah Liflyand

Variations on the theorems of F. and M. Riesz and of Hardy and Littlewood -337

Vakhtang Tsagareishvili

Information-preserving operators — 343

Hua Wang

Boundedness of intrinsic square functions on generalized Morrey spaces _ 351

Chun Wu

Normal criteria of meromorphic functions and shared functions -369 